\title{
Heart Rate Variability at rest and after the 6-minute walk test (6MWT) in children with cystic fibrosis
}

\author{
Rêncio Florêncio ${ }^{1}$, Guilherme Fregonezi ${ }^{1}$, Silvia Brilhante ${ }^{1}$, \\ Audrey Borghi-Silva ${ }^{2}$, Fernando Dias ${ }^{1}$, Vanessa Resqueti ${ }^{1}$
}

\begin{abstract}
Background: Cystic fibrosis (CF) is a multisystem disease that affects the cardiorespiratory system and the cardiac autonomic control may be altered at rest and after a submaximal exercise. Objective: To assess the cardiac autonomic control by heart rate variability (HRV) analysis before and after a 6-minute walk test (6MWT). Method: Thirteen children diagnosed with Cystic Fibrosis (CFG) aged 12 \pm 2.7 years (FEV,FVC: $0.83 \pm 0.11, F_{1}: 71.4 \pm 21 \%$ pred) and 12 healthy children (control group-CG) aged 11.4 \pm 2.4 years (FEV,/FVC: $0.91 \pm 0.12, \mathrm{FEV}_{1}:$ 91.6 $\pm 17.4 \%$ pred) were included in the study. HRV was evaluated prior to and immediately after the 6MWT and the heart rate recovery assessed on the first and second minute after test. Results: Prior to exercise, CF patients presented higher values for the variables $\mathrm{LF}_{\text {nu }}(53.2 \pm 15.0$ vs. $32.8 \pm 7.9, p=0.0003)$ and $\mathrm{LF} / \mathrm{HF}(1.25 \pm 0.72 v s .0 .49 \pm 0.18, p<0.006)$ as well as lower values of $\mathrm{HF}_{\%}$ $(25.4 \pm 18.4$ vs. $53 \pm 9.6, p=0.002)$ and $\mathrm{HF}_{\text {nu }}(47.3 \pm 14.7$ vs. 68.3 $\pm 8.7, p 0.001)$ when compared to CG. After the 6MWT, both groups demonstrated HRV recovery to baseline levels; however, the differences between CFG and CG were maintained for the variables $\mathrm{LF}_{(\mathrm{ms})}^{2}(846.7 \pm 754.8 v s .345 .6 \pm 197.2, p=0.02) ; \mathrm{LF}_{\%}(35.4 \pm 8.1$ vs. 25.9 $\pm 6.2, p=0.002) ; \mathrm{LF}_{\mathrm{nu}}(60.0 \pm 16.3$ vs. 34.9 $\pm 8.7, p<0.0001) ; \mathrm{HF}_{\%}(27.4 \pm 13.7$ vs. 48.1 $\pm 6.3, p=0.0003) ; \mathrm{HF}_{\mathrm{nu}}(40.4 \pm 15.8$ vs. $65.6 \pm 8.2, p=0.0003)$ and LF/ HF (1.9 \pm 1.7 vs. $0.5 \pm 0.2, p=0.0001)$. Conclusions: Children with cystic fibrosis exhibited predominance of sympathetic activity at rest that persisted after the 6-minute walking test when compared to the control group.
\end{abstract}

Keywords: physical therapy specialty; cystic fibrosis; heart rate; autonomic nervous system; exercise.

\section{HOW TO CITE THIS ARTICLE}

Florêncio R, Fregonezi G, Brilhante S, Borghi-Silva A, Dias F, Resqueti V. Heart rate variability at rest and after the 6-minute walk test (6MWT) in children with cystic fibrosis. Braz J Phys Ther. 2013 Sept-Oct; 17(5):419-426. http://dx.doi.org/10.1590/ S1413-35552012005000109

\section{Introduction}

Cystic fibrosis (CF) is a hereditary disease transmitted as an autosomal recessive trait characterized by generalized dysfunction of the exocrine glands. It is a chronic disease that compromises the function of almost all organs and systems ${ }^{1}$. Lung alterations are among the main clinical manifestations and result in obstruction of small airways and trigger a chronic inflammatory process. In association to respiratory dysfunction, cardiac damage may also be present and manifested by signs and symptoms of right ventricular dysfunction. Although the initial and primary symptom reported by CF patients is dyspnea, other factors such as tachycardia due to $\beta$ - 2 agonist use and hypoxemia may contribute to cardiac autonomic dysfunction.

The interaction between cardiac and pulmonary dysfunction in CF patients, may influence the autonomic nervous system controlling the heart and consequently, the spectral analysis of R-R interval

oscillations. Changes in heart rate variability (HRV) patterns are a sensitive and early indicator of damage to the cardiac system ${ }^{2}$. In adult CF sufferers, a significant relationship between lung disease severity $\left(\mathrm{FEV}_{1 \% \text { pred }}\right)$ and elevated HF power $\left(\mathrm{ms}^{2}\right)$ or lower $\mathrm{LF} /$ HF ratio was reported ${ }^{3}$. This observation suggests that the progression of the disease is associated to decreased sympathetic predominance of autonomic heart control.

In $\mathrm{CF}$ patients, the exercise intolerance has been associated to higher mortality ${ }^{4}$. Cardiovascular dysfunction was described in CF patients and autonomic neuropathy has also being suggested ${ }^{5}$; however, there is paucity of data regarding cardiac autonomic control and heart rate (HR) recovery after a submaximal exercise in this population as well as in healthy children. The 6-minute walk test (6MWT) is a submaximal and safe test used in patients with $\mathrm{CF}$. The HR peak reached during the test was recently

\footnotetext{
${ }^{1}$ PneumoCardioVascular and Respiratory Muscle Performance Laboratory, Department of Physical Therapy, 
report to be a simple alternative parameter to guide exercise prescription in this population ${ }^{6}$. Furthermore, the rate of HR recovery to baseline values after exercise, probable representing the kinetics of vagal tone recovery, has been associated with fitness and good health ${ }^{7}$. In the present study, we hypothesized that alterations in cardiac autonomic modulation in $\mathrm{CF}$ children would interfere in submaximal exercise performance and HR recovery. Given the importance of introducing an aerobic and respiratory physical therapy program to CF patients a better understanding of parameters such as HRV and HR recovery during exercise is valuable to improve the prescription and monitoring of rehabilitation programs based on physical exercise.

Therefore, the main objective of the present study was to assess HRV at rest and the HR recovery, as well as the HRV recovery, following the 6MWT in children with $\mathrm{CF}$ and age matched healthy controls.

\section{Method}

This is an observational cross-sectional study. Participants were submitted to a previously scheduled outpatient evaluation performed by a single trained examiner. The study was approved by the Research Ethics Committee of the University Hospital Onofre Lopes, Natal, Rio Grande do Norte, Brazil, under the protocol number 497/10. All subjects and their guardians were informed of the study aims and gave written consent, in accordance with of the Brazilian National Health Council resolution 196/96.

\section{Sample}

Subjects were divided into two groups: the cystic fibrosis group (CFG) and control group (CG). The sample consisted of patients diagnosed with $\mathrm{CF}$, treated by the Multidisciplinary Cystic Fibrosis Group from the Pediatric Outpatient Clinic of the University Hospital. The multidisciplinary team was composed of a pediatrician, pulmonologist, gastroenterologist, psychologist, dietician, nurse and physical therapist. The CG was composed of healthy children matched by age, with no previous cardiopulmonary disease. Subjects were from both sexes, older than 8 years and capable of performing a pulmonary function examination, a respiratory muscle strength test, a 6MWT and the HRV testing. All patients were in stable medical condition, without exacerbation of the disease ${ }^{8}$ in the previous 3 week and receiving regular treatment consisting of inhaled bronchodilators. Four patients were prescribed betablockers (salbutamol) and antibiotics (ciprofloxacin, gentamicin) which were discontinued 24 hours prior to the tests. Patients unable to perform the submaximal test, as well as those who request to be withdrawn or were absent during the scheduled tests were excluded from the study.

\section{Study design}

Following selection, participants and their guardians were informed as to the nature of the research and completed an identification form. Individuals who satisfied all the inclusion criteria were asked to give their informed consent. Evaluations took place on two separated days, with a maximum of one week apart. On the first day, subjects were submitted to anthropometric assessment as well as pulmonary function and respiratory muscle strength tests. The second day of evaluation was divided into three periods: HRV assessment at rest in the supine position, during 20 minutes (period A); 6MWT (period B) and HRV analysis following the 6MWT in the supine position during 20 minutes (period C).

\section{Anthropometric measurements}

Anthropometric assessment consisted of measuring body weight, height and body mass index (BMI). Percentile values of BMI were used for anthropometric characterization of the sample applying cutoff values recommended by the World Health Organization $(\mathrm{WHO})^{9}$. Participants were measured and weighed in anatomical position on a $150 \mathrm{Kg}$-capacity mechanical scale, with accuracy of $100 \mathrm{~g}$ (Welmy ${ }^{\circledR}$, Santa Bárbara do Oeste, Paraná, Brazil) coupled to a stadiometer. Weight and height were measured with patients standing upright, barefoot and wearing lightweight clothing.

\section{Assessment of pulmonary function}

Technical criteria for acceptability and reproducibility of the tests were in accordance with spirometry guidelines from the Brazilian Society of Pulmonology and Tuberculosis (SBPT) $)^{10}$. All participants received prior instructions from the examiner on how to correctly execute the maneuvers. Subjects were asked to perform a maximal inspiration close to total lung capacity (TLC) followed by a rapid and sustained expiration until instructed to stop by the examiner. The following variables were assessed during spirometry: $\mathrm{FVC}, \mathrm{FEV}_{1}, \mathrm{FEF}_{25-75 \%}$ and $\mathrm{FEV}_{1} / \mathrm{FVC}$. The evaluation was considered complete when two out of three acceptable curves were reproducible. Results obtained in absolute and relative values as well as the highest spirometric 
values, within reproducible curves, were considered for analysis. Findings were compared to reference values validated for Brazilian children ${ }^{11}$. Spirometry was performed using a DATOSPIR spirometer (Sibelmed, Barcelona, Spain).

\section{Respiratory muscle strength}

Inspiratory and expiratory muscle strength was evaluated using sustained plateau pressure during a maximal inspiration and expiration; respectively. Pressure was measured using the MicroRPM digital manometer (MICRO medical, Rochester, Kent, United Kingdom). Participants received instructions prior to the test and the maneuvers were demonstrated by the examiner. Technical criteria of acceptability and reproducibility for maximal respiratory pressure test followed SBPT guidelines ${ }^{12}$. Individuals were first requested to perform a maneuver for learning purposes and evaluation was deemed complete when two out of three acceptable measurements were reproducible. The greatest value obtained in the reproducible measurements was considered for analysis.

\section{Six-minute walk test (6MWT) and HR recovery}

The walking test was conducted according to previously described protocol ${ }^{13,14}$ and results were recorded on a standardized chart. Participants were asked to walk back and forth along a flat, 30-meter long corridor as far and as fast as possible during the 6-minute period. The examiner monitored HR and oxygen saturation during all test using a Polar S810i HR monitor (Polar Electro Inc., New York, USA) and a Palmsat portable pulse oximeter (Nonin Medical, Minnesota, USA); respectively. A standardized phrase of encouragement was given every minute. On completion, total distance walked was calculated and results were compared to reference values for Brazilian children aged 6 to $12^{15}$ years or older than 13 years $^{16}$. Subjective symptoms of perceived dyspnea and exhaustion were measured before and immediately after the test using a modified Borg scale with values ranging from 1 to $10{ }^{17}$. HR and oxygen saturation were assessed at rest and in the first and second minute following testing.

HR recovery was calculated based on the difference between the maximum HR reached during the 6MWT and the HR at the first and second minute after the test?

\section{Heart Rate Variability (HRV)}

Participants were evaluated in the morning to avoid circadian influence on the results. Temperature in the laboratory was maintained between $22^{\circ} \mathrm{C}$ and $24{ }^{\circ} \mathrm{C}$. All participants were informed of the protocol, instructed to abstain from ingesting stimulants in the 24 hours prior to the test and have a light meal at least 2 hours before assessment. On the day of the test, subjects were questioned and examined to ascertain their general well-being and a good night of sleep (7-8 hours). After a 20-minute rest, systemic blood pressure (Missouri-Mikato, SP, Brazil) and radial pulse (Nonin Medical, MN, USA) were measured to determine whether baseline conditions were suitable for the test. To obtain RR intervals, subjects were monitored in the supine position for 20 minutes, before and after the 6MWT, using a Polar S810 $i^{\circledR}$ HR monitor (Polar Electro Inc., New York, USA). Cardiac electrical signal were monitored by two electrodes connected to the Polar device and positioned on the skin surface one at the area of the xiphoid process and another on the anterior axillary line, at nipple height. Data obtained by the monitor were transferred to a computer via an infrared interface device. This system detects ventricular depolarization, corresponding to the $\mathrm{R}$ wave of the electrocardiogram (ECG), with a sampling rate of $500 \mathrm{~Hz}$ and temporal resolution of 1 millisecond $^{18}$ and was previously validated by Vanderlei et al. ${ }^{2}$. HR signals were processed to calculate HRV values using the Kubios HRV program (version 2.0 MATLAB, MathWorks Inc., Kuopio, Finland), based on RR intervals obtained by the device. HRV was analyzed in the frequency domain, using the area of greatest stability in RR intervals, provided these exhibited at least 256 consecutive beats. Frequency domains were analyzed by Fast Fourier Transform applied in a single window, after subtracting the linear tendency using automatic filters in previously selected RR intervals. The domains were studied using low (LF: 0.04 to $0.15 \mathrm{~Hz}$ ) and high (HF: 0.15 to $0.4 \mathrm{~Hz}$ ) frequency ranges in spectral density $\left(\mathrm{ms}^{2}\right)$, power $(\%)$ and normalized units (nu). LF/HF ratio was also calculated. During data collection, volunteers were instructed to remain at rest in the supine position, without moving and/or crossing any limbs or speaking to those present.

\section{Statistical analysis}

Data are presented as means and standard deviation. The Shapiro-Wilk test was applied to establish data normality, followed by the Student's t-test to compare anthropometric, spirometric and 
HRV variables intragroup and intergroup. Pearson's correlation coefficient was used to determine the correlation between variables. A $p$ value $<0.05$ was the criterion for statistical significance. The GraphPad Prism ${ }^{\circledR}$.0 program for Windows (GraphPad Software, San Diego California USA) was used for all analyses.

\section{Results}

The final sample consisted of 13 children ( 6 boys) suffering from $C F$ with a mean age of $12 \pm 2.7$ years and 12 healthy subjects (6 boys) with a mean age of $11.4 \pm 2.4$ years. One child (CFG) was excluded due to voluntary withdrawal request during data collection. Table 1 demonstrates that anthropometric variables for weight, height and BMI were not significantly different between groups. According to cutoff values for BMI percentiles suggested by the World Health Organization (WHO) ${ }^{9}$, only two children in the CFG had low (15.4\%) BMI for their age and the other 11 $(84.6 \%)$ exhibited BMI within the normal range. In the CG, only one subject (8.3\%) was classified with low BMI, nine subjects (75\%) presented normal BMI for their age and two subjects (16.7\%) were deemed overweight.

As expected, significant differences were recorded between spirometric variables of the $\mathrm{CFG}$ in relation to controls for $\mathrm{FEV}_{1}(p=0.03), \mathrm{FEV}_{1}(\%)(p=0.03)$, $\mathrm{FEF}_{25-75 \%}(p=0.004), \mathrm{FEF}_{25-75}(p=0,03)$ and $\mathrm{FEV}_{1} /$
FVC\% $(p=0.03)$, as summarized in Table 1 . The CFG showed mean $\mathrm{FEV}_{1}(\%)$ lower than $80 \%$, characterizing an obstructive pattern. With regard to respiratory muscle strength, no significant intergroup differences were found.

Surprisingly, no significant inter-group differences were recorded in distance walked in the 6MWT (CFG: $579.5 \pm 58$ vs. CG: $600 \pm 30$ meters, $p=0.36$ ). However, CFG demonstrated a sluggish HR recovery in the first and second minutes after exercise when compared to controls (Table 2).

Data from HRV analysis both at the baseline and during the recovery from the 6MWT are summarized on Figures 1 and 2. Before the 6MWT, LFnu ( $p=0.0003)$, HF\% ( $p=0.002)$, HFnu $(p=0.002)$ and $\mathrm{LF} / \mathrm{HF}$ ratio $(p=0.006)$ were different between CFG and CG. Even though both groups showed a recovery in HRV parameters comparable to preexercise values, the differences between CFG and controls persisted for LF $\left(\mathrm{ms}^{2}\right)(p=0.027), \mathrm{LF} \%$ $(p=0.002)$, LFnu $(p<0.0001)$, HF\% $(p=0.0003)$, HFnu $(p=0.0003)$ and the LF/HF ratio $(p=0.0001)$. No correlations were found between the variables studied.

\section{Discussion}

The present study assessed the HRV at rest and during the recovery time following the 6MWT in patients children with $\mathrm{CF}$ and age-matched healthy

Table 1. Anthropometric characteristics and pulmonary function test of the study population.

\begin{tabular}{|c|c|c|c|}
\hline Variables & Cystic Fibrosis Group $(\mathrm{n}=13)$ & Control Group $(n=12)$ & $p$ value \\
\hline Sex (M:F) & $6: 7$ & $6: 6$ & - \\
\hline Age (years) & $12 \pm 2.7$ & $11.2 \pm 2.4$ & 0.42 \\
\hline Height $(\mathrm{cm})$ & $142.4 \pm 10.9$ & $147.5 \pm 14.7$ & 0.31 \\
\hline Weight (Kg) & $34.6 \pm 8.5$ & $38.4 \pm 9$ & 0.34 \\
\hline $\mathrm{FVC}(\mathrm{L})$ & $1.91 \pm 0.6$ & $2.50 \pm 0.9$ & 0.07 \\
\hline FVC (\%pred) & $80.8 \pm 22.3$ & $93.6 \pm 18.8$ & 0.13 \\
\hline $\mathrm{FEV}_{1}(\mathrm{~L})$ & $1.6 \pm 0.5$ & $2.3 \pm 0.7$ & $0.009 * *$ \\
\hline $\mathrm{FEV}_{1}(\%$ pred $)$ & $71.4 \pm 21$ & $91.5 \pm 17.3$ & $0.01 *$ \\
\hline $\mathrm{FEF}_{25-75 \%}(\mathrm{~L} / \mathrm{s})$ & $1.8 \pm 0.7$ & $2.86 \pm 0.9$ & $0.004 * *$ \\
\hline $\mathrm{FEF}_{25-75 \%}(\%$ pred $)$ & $69.6 \pm 19.7$ & $90.5 \pm 19.4$ & $0.002 * *$ \\
\hline $\mathrm{FEV}_{1} / \mathrm{FVC}$ & $0.83 \pm 0.1$ & $0.93 \pm 0.1$ & $0.03 *$ \\
\hline PImáx $\left(\mathrm{cmH}_{2} \mathrm{O}\right)$ & $87.6 \pm 23.4$ & $87.6 \pm 20.4$ & 0.99 \\
\hline PEmáx $\left(\mathrm{cmH}_{2} \mathrm{O}\right)$ & $96 \pm 27.3$ & $111.1 \pm 16.9$ & 0.11 \\
\hline
\end{tabular}

Values represent mean \pm standard deviation. M: male; F: female; BMI: body mass index. FVC: forced vital capacity; FEV : forced expiratory volume in the first second; $\mathrm{FEF}_{25-75 \%}$ : mean forced expiratory flow between 25 and $75 \%$; PImáx: maximal inspiratory pressure; PEmáx: maximal expiratory pressure. $* p<0.05$ and $* * x<0.01$ (unpaired t-test). 
Table 2. Variables values obtained from the six-minute walk test (6MWT).

\begin{tabular}{|c|c|c|c|}
\hline Variables & Cystic Fibrosis Group $(n=13)$ & Control Group $(n=12)$ & $p$ value \\
\hline HRrest (bpm) & $94.8 \pm 19$ & $94 \pm 7.7$ & 0.89 \\
\hline $\operatorname{HRmax}(\mathrm{bpm})$ & $138.2 \pm 13.1$ & $143.5 \pm 11.7$ & 0.30 \\
\hline$\Delta$ HRmax-rest & $43.3 \pm 14$ & $49.4 \pm 12.8$ & 0.27 \\
\hline HRrecov $1 \mathrm{~min}$ & $114.3 \pm 16$ & $109.6 \pm 15.1$ & 0.45 \\
\hline HRrecov $2 \mathrm{~min}$ & $104.8 \pm 17$ & $99.6 \pm 14.3$ & 0.41 \\
\hline $\operatorname{HRmax}(\%)$ & $66.9 \pm 5.6$ & $69 \pm 6$ & 0.42 \\
\hline$\Delta \mathrm{HRmax}{ }_{\text {recovlmin }}$ & $23.8 \pm 11.2$ & $33.9 \pm 7.4$ & $0.01 *$ \\
\hline$\Delta \mathrm{HRmax}_{\text {recov2min }}$ & $33.3 \pm 14.2$ & $44 \pm 9.9$ & $0.04 *$ \\
\hline $\mathrm{SpO}_{2 \text { before } 6 \mathrm{MWT}}$ & $97.1 \pm 2.5$ & $98.5 \pm 0.6$ & 0.08 \\
\hline $\mathrm{SpO}_{2 \text { after } 6 \mathrm{MWT}}$ & $96.5 \pm 3.0$ & $98.1 \pm 0.8$ & 0.10 \\
\hline Distance (m) & $579.5 \pm 57.7$ & $600 \pm 30$ & 0.28 \\
\hline
\end{tabular}

Values represent mean \pm standard deviation. HRmax: maximum heart rate; DHR max-rest: difference between the maximum heart rate and resting heart rate; HRrecov: recovery heart rate; $\mathrm{DHRmax}$-recov: difference between the maximum heart rate and minute recovery rate; $\mathrm{SpO}_{2}$ : peripheral oxygen saturation. ${ }^{*} p<0.05$ (unpaired t-test).
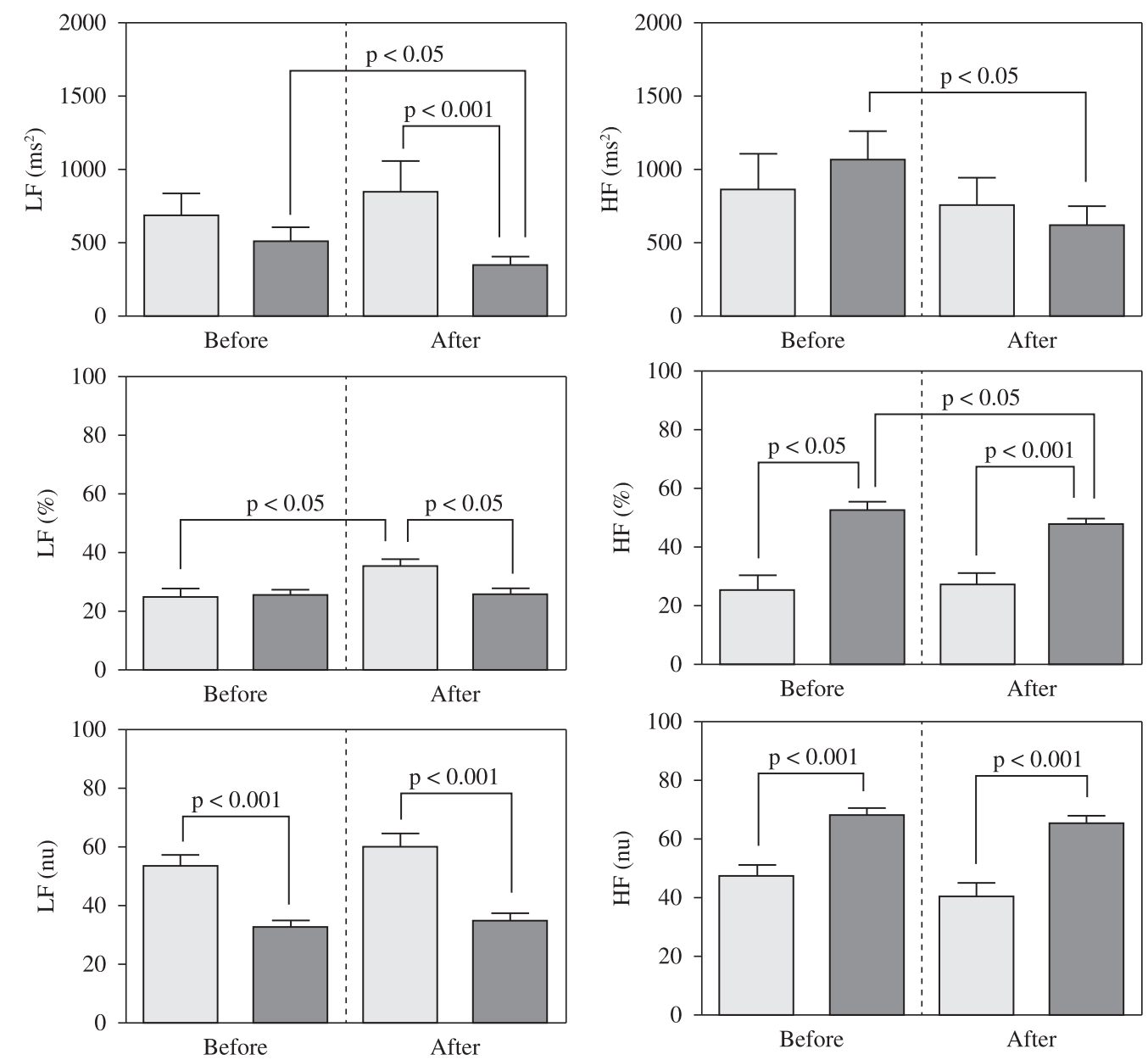

$\square$ Cystic fibrosis group (CFG) $\square$ Control group (CG)

Figure 1. Comparison of HRV before and after the six-minute walk test in children with Cystic Fibrosis and the Control Group. Values represent mean \pm standard deviation. LF: Low Frequency; HF: High Frequency. Paired t-test used for intragroup comparison and unpaired t-test used for intergroup comparison. 


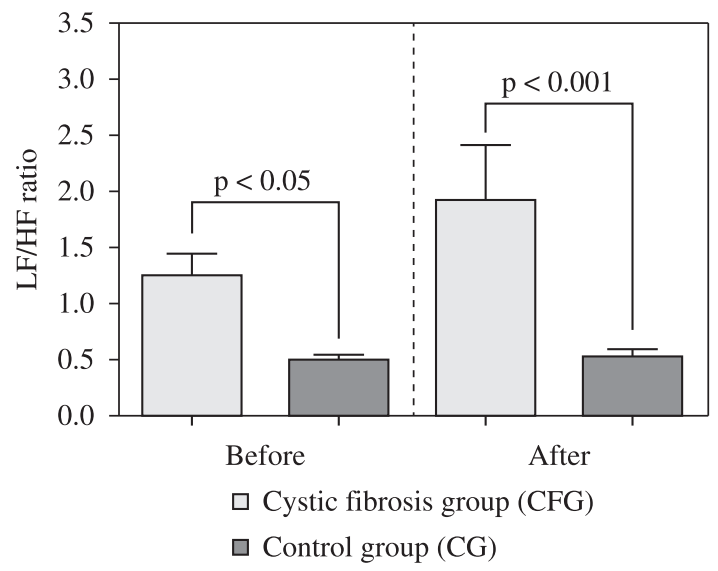

Figure 2. Comparison of low and high frequency ratio (LF/ $\mathrm{HF}$ ) before and after six-minute walk test in both groups. Values represent mean \pm standard deviation. LF: Low Frequency; HF: High Frequency. Unpaired t-test was used for intergroup comparison.

controls. Analyzing the cardiac autonomic control, the CFG exhibited sympathovagal balance variations during the 6MWT similar to healthy controls; however, both at rest and during the recovery time, the CFG demonstrated increased sympathetic and decreased parasympathetic activity. To our knowledge, HRV after submaximal exercise in children with CF has not been previously studied.

Our data demonstrate a higher sympathetic activity at baseline in the CFG compared to controls represented by higher values for LFnu and a higher $\mathrm{LF} / \mathrm{HF}$ ratio. Both groups demonstrate similar HRV recovery after the 6MWT during the period of time the R-R signal was collected; however, the sympathetic predominance was still present in CFG during the recovery time. It is possible that along the years, this sustained higher sympathetic stimulation may have a role in the pathophysiology of cardiovascular disease in this population. This observation deserves further investigation.

Szollosi et al. ${ }^{3}$ investigated 17 young adults (28.8 \pm 9.1 years) with CF and compared them with 17 healthy subjects. HRV was evaluated with volunteers in the supine position breathing spontaneously for 15 minutes followed by assessment during controlled breathing at 15 breaths per minute. The authors observed that during normal breathing, $\mathrm{CF}$ sufferers showed a tendency to lower LF values when compared to healthy controls [ $\mathrm{LF}\left(\mathrm{In} \mathrm{ms}^{2}\right)$ : $2.6 \pm 0.5$ vs. $2.8 \pm 0.4, p=0.07]$. No differences were observed using controlled breathing. In contrast to the findings of Szollosi et al. ${ }^{3}$, in the present study, children with $\mathrm{CF}$ demonstrated significantly higher
LF values at rest compared to healthy individuals. This higher sympathetic drive can also be identified by the higher LF/HF ratio in CFG at baseline. The plausible explanation of these results may be due to alterations of respiratory pattern ${ }^{19}$, higher levels of catecholamine ${ }^{20}$ or higher work of breathing ${ }^{21}$; however, these mechanisms remain speculative at this time. Szollosi et al. ${ }^{3}$ also found a negative correlation between $\mathrm{FEV}_{1} \%$ and $\mathrm{HF}\left(\mathrm{ms}^{2}\right)$ during spontaneous (r: -0.54) and controlled (r: -0.57$)$ breathing and a positive correlation between $\mathrm{FEV}_{1} \%$ and LF/HF ratio (r: 0.69) demonstrating a higher parasympathetic activation in patients presenting more obstruction to airflow. In the present study, we did not find correlations between HRV parameters and $\mathrm{FEV}_{1} \%$; however, the mean $\mathrm{FEV}_{1} \%$ was slightly higher in our population compared to Szollosi et al. ${ }^{3}$. In fact, as discussed before there is a predominance of sympathetic stimulation in children with CF. Furthermore, in $50 \%$ of CF patients the variation of $\mathrm{LF} / \mathrm{HF}$ ratio did not return to baseline values. It is possible to speculate that the progression of the obstructive disease associated to a desensitization of the $\beta$-adrenergic receptors in $\mathrm{CF}$ patients consequent to chronic use of $\beta$-adrenergic agonist may explain the reversal of a sympathetic predominance to a lower HRV and parasympathetic predominance in the adult with $\mathrm{CF}$.

HR recovery after exercise is mediated by vagal reactivation and decrease in sympathetic stimulation ${ }^{22}$. The rate of HR recovery appears to be a reflection of a faster recovery from the sympathetic drive necessary during exercise. Increased vagal activity associated with a faster HR recovery has been shown to be associated with a decrease in risk of death ${ }^{23}$. In the present study, the rate of HR recovery was slower in CFG. This can be an indication of slower recovery of the sympathovagal balance. It is important to point out that even though HRV returned close to baseline values in CFG this measurement reflects the average data of a period of approximately 5 minutes, therefore it does not reflect minute by minute changes in HRV. Measurements of HR recovery minute by minute give us an estimate of time-dependent HRV recovery. These results potentially have a high level of clinical relevance given that disorders of cardiac autonomic control have been associated with the development of arrhythmias ${ }^{24}$ and sudden death ${ }^{25}$ in the chronic obstructive disease population. Longitudinal data assessing the impact of cardiac autonomic dysfunction in cystic fibrosis group (CFG) is not available at the moment. HRV recovery assessment after exercise may prove valuable in assessing risk 
during different therapeutic interventions ${ }^{26}$ such as physical exercise ${ }^{27}$.

HRV has also been evaluated in other patients presenting pulmonary obstructive disease. Volterrani et al. ${ }^{28}$, investigated HRV in 31 male COPD patients under 3 different conditions: normal breathing in the supine position, controlled breathing in the supine position and passive orthostasis (standing upright). The authors ${ }^{28}$ found that parasympathetic activity on HR in patients with COPD was $57 \%$ higher when compared to the $\mathrm{CG}$, at rest and supine position [HFnu: $44 \pm 27 v s$. $28 \pm 18, p<0.05]$. In contrast, Borghi-Silva et al. ${ }^{27}$ demonstrated that severe COPD was associated with higher sympathetic and reduced parasympathetic activity at rest and during exercise. In addition, these authors showed that an aerobic training program favorably impacted the disarrangement in autonomic modulation of HR. In this context, future research in this area is needed to address the impact of a physical training program on autonomic nervous control of HR in CF patients. Findings from the present study cannot be directly compared to results presented by Volterrani et al. ${ }^{28}$ and Borghi-Silva et al. ${ }^{27}$, due to differences in methodology and population studied. It is important to underscore that the present study recorded a decline in vagal activity in the pre-exercise period in $\mathrm{CF}$ patients when compared to healthy subjects. Physiologically, respiratory control is modulated via afferent supply by the vagus nerve, which in turn modulates sinoatrial node activity. Reflex interactions between respiration and HR are also known. In situations where breathing pattern and lung volumes are altered (e.g. changing lung mechanoreceptor discharge) such as lung diseases involving obstructed airflow, it can be expected that HR control may eventually be affected.

Due to the noninvasive nature of our study, several methodological aspects could be questioned. Although it was not possible to directly measure respiratory pattern, we believe that this variable could have an important role in the cardiac autonomic control alterations that we observed. Secondly, we measured the cardiac autonomic nervous system control of HR by HRV, a noninvasive measurement. We believed that catecholamine levels or quantification of inflammatory markers could help explain our results. However, due to the population studied (children) invasive methods were not chosen. Nonetheless, HRV has been widely used and is an important tool to study cardiac autonomic control and also has been validated by previous studies including methods such as pharmacologic blockage of receptor involved in autonomic control ${ }^{29}$. Finally, a larger number of participants would be ideal; however, the strict inclusion criteria and the fact that $\mathrm{CF}$ is not a common lung disease made recruitment of volunteers difficult.

\section{Conclusion}

The results from the present study demonstrate that children with CF exhibit increased sympathetic heart modulation before and after a submaximal exercise test when compared with healthy children. In addition, sluggish HR recovery was observed in children with $\mathrm{CF}$.

\section{References}

1. Coelho CC, Aquino ES, De Almeida DC, Oliveira GC, Pinto RC, Rezende IMO, et al. Comparative analysis and reproducibility of the modified shuttle walk test in normal children and in children with cystic fibrosis. J Bras Pneumol. 2007;33(2):168-174. PMid:17724536. http:// dx.doi.org/10.1590/S1806-37132007000200011

2. Vanderlei LCM, Pastre CM, Hoshi RA, Carvalho TD, Godoy MF. Basic notions of heart rate variability and its clinical applicability. Rev Bras Cir Cardiovasc. 2009 Apr-Jun;24(2):205-17. PMid:19768301. http://dx.doi. org/10.1590/S0102-76382009000200018

3. Szollosi I, King SJ, Wilson JW, Naughton MT. Tachycardia in adults with cystic fibrosis is associated with normal autonomic function. Intern Med J. 2011 Jun; 41(6):45561. http://dx.doi.org/10.1111/j.1445-5994.2009.02039.x

4. Bradley J, Moran F. Physical training for cystic fibrosis. Cochrane Database Syst Rev. 2008;(1):CD002768. PMid:18254007.

5. Mirakhur A, Walshaw MJ. Autonomic dysfunction in cystic fibrosis. J R Soc Med. 2003;96(Suppl.43):11-17. PMid:12906320 PMCid:PMC1308782.

6. Gruet M, Brisswalter J, Mely L, Vallier J-M. Use of the peak heart rate reached during six-minute walk test to predict individualized training intensity in patients with cystic fibrosis: validity and reliability. Arch Phys Med Rehabil. 2010 Apr;91(4):602-7. PMid:20382294. http:// dx.doi.org/10.1016/j.apmr.2009.12.008

7. Shetler K, Marcus R, Froelicher VF, Vora S, Kalisetti $\mathrm{D}$, Prakash $\mathrm{M}$, et al. Heart rate recovery: validation and methodologic issues. J Am Coll Cardiol. 2001 Dec;38(7):1980-7. http://dx.doi.org/10.1016/ S0735-1097(01)01652-7

8. Flume PA, Mogayzel PJ Jr, Robinson KA, Goss CH, Rosenblatt RL, Kuhn RJ, et al. Cystic fibrosis pulmonary guidelines: treatment of pulmonary exacerbations. Am J Respir Crit Care Med 2009; 180:802-8. PMid:19729669. http://dx.doi.org/10.1164/rccm.200812-1845PP

9. World Health Organization - WHO. WHO Growht reference data for 5-19 years: body mass index-for-age. 
2007 [cited 2012 Apr 16]. Available from: http://www. who.int/growthref/en/.

10. Pereira CAC; Sociedade Brasileira de Pneumologia e Tisiologia - SBPT. Diretrizes para testes de função pulmonar. J Bras Pneumol. 2002;28 Suppl 3:S01-82.

11. Beydon N, Davis SD, Lombardi E, Allen JL, Arets HGM, Aurora P. An official American Thoracic Society/ European Respiratory Society statement: Pulmonary function testing in preschool children. Am J Respir Crit Care Med. 2007;175:1304-1345. PMid:17545458. http:// dx.doi.org/10.1164/rccm.200605-642ST

12. Souza RB; Sociedade Brasileira de Pneumologia e Tisiologia - SBPT. Diretrizes para testes de função pulmonar. J Bras Pneumol. 2002;28 Suppl3:S155-65.

13. Guyatt G, Pugsley S, Sullivan M, Thompson PJ, Berman $\mathrm{L}$, Jones NL, et al. Effect of encouragement on walking test performance. Thorax. 1984 Nov;39(11):818-22. PMid:6505988 PMCid:PMC459930. http://dx.doi. org/10.1136/thx.39.11.818

14. American Thoracic Society - ATS. ATS statement: guidelines for six minute walk test. Am J Respir Crit Care Med. 2002 Jul 1;166(1):111-7. PMid:12091180. http:// dx.doi.org/10.1164/ajrccm.166.1.at1102

15. Priesnitz CV, Rodrigues GH, Stumpf CS, Viapiana G, Cabral CP, Stein RT, et al. Reference values for the 6-min walk test in healthy children aged 6-12 years. Pediatr Pulmonol. 2009 Dec;44(12):1174-9. PMid:19911357. http://dx.doi.org/10.1002/ppul.21062

16. Iwama AM, Andrade GN, Shima P, Tanni SE, Godoy I, Dourado VZ. The six-minute walk test and body weightwalk distance product in healthy Brazilian subjects. Braz J Med Biol Res. 2009 Nov;42(11):1080-5. PMid:19802464. http://dx.doi.org/10.1590/S0100-879X2009005000032

17. Wilson RC, Jones PW. A comparison of the visual analogue scale and modified Borg scale for the measurement of dyspnoea during exercise. Clin Sci (Lond). 1989 Mar;76(3):277-82.

18. Perini R, Veicsteinas A. Heart rate variability and autonomic activity at rest and during exercise in various physiological conditions. Eur J Appl Physiol. 2003 Oct;90(3-4):317-25. PMid:13680241. http://dx.doi. org/10.1007/s00421-003-0953-9

19. Pöyhönen M, Syväoja S, Hartikainen J, Ruokonen E, Takala J. The effect of carbon dioxide, respiratory rate and tidal volume on human heart rate variability. Acta Anaesthesiol Scand. 2004 Jan;48(1):93-101. PMid:14674979. http:// dx.doi.org/10.1111/j.1399-6576.2004.00272.x

20. Zouhal H, Jacob C, Delamarche P, Gratas-Delamarche A. Catecholamines and the effects of exercise, training and gender. Sports Med. 2008;38(5):401-23. PMid:18416594. http://dx.doi.org/10.2165/00007256-200838050-00004

21. Heindl S, Lehnert M, Crie'e CP, Hasenfuss G, Andreas $\mathrm{S}$. Marked sympathetic activation in patients with chronic respiratory failure. Am J Respir Crit Care Med. 2001
Aug 15;164(4):597-601. PMid:11520722. http://dx.doi. org/10.1164/ajrccm.164.4.2007085

22. Almeida MB, Araújo CGS. Effects of aerobic training on heart rate. Rev Bras Ciênc Esporte. 2003 Mar-Abr;9(2):113-20.

23. Hull SS Jr, Vanoli E, Adamson PB, De Ferrari GM, Foreman RD, Schwartz PJ. Do increases in markers of vagal activity imply protection from sudden death? The case of scopolamine. Circulation. 1995 May 15;91(10):2516-9. PMid:7743612. http://dx.doi. org/10.1161/01.CIR.91.10.2516

24. Tükek T, YildizP, Atilgan D, Tuzcu V, Eren M, Erk O, et al. Effect of diurnal variability of heart rate on development of arrhythmia in patients with chronic obstructive pulmonary disease. Int J Cardiol. 2003 Apr;88(2-3):199-206. http:// dx.doi.org/10.1016/S0167-5273(02)00402-3

25. Kleiger RE, Senior RM. Long-term electrocardiographic monitoring of ambulatory patients with chronic airway obstruction. Chest. 1974 May;65(5):483-7. PMid:4274977. http://dx.doi.org/10.1378/chest.65.5.483

26. Borghi-Silva A, Reis MS, Mendes RG, Pantoni CB, Simões RP, Martins LE, et al. Noninvasive ventilation acutely modifies heart rate variability in chronic obstructive pulmonary disease patients. Respiratory Medicine. 2008 Aug;102(8):1117-23. PMid:18585024. http://dx.doi.org/10.1016/j.rmed.2008.03.016

27. Borghi-Silva A, Arena R, Castello V, Simões RP, Martins LE, Catai AM, et al. Aerobic exercise training improves autonomic nervous control in patients with COPD. Respir Med. 2009 Oct;103(10):1503-10. PMid:19464865. http:// dx.doi.org/10.1016/j.rmed.2009.04.015

28. Volterrani M, Scalvini S, Mazzuero G, Lanfranchi $\mathrm{P}$, Colombo R, Clark AL, et al. Decreased heart rate variability in patients with chronic obstructive pulmonary disease. Chest. 1994 Nov;106(5):1432-7. PMid:7956396. http://dx.doi.org/10.1378/chest.106.5.1432

29. Task Force of the European Society of Cardiology and the North American Society of Pacing and Electrophysiology. Heart rate variability: standards of measurements, physiological interpretation, and clinical use. Circulation. 1996 Mar 1;93(5):1043-65. PMid:8598068. http://dx.doi. org/10.1161/01.CIR.93.5.1043

\section{Correspondence}

\section{Vanessa Resqueti}

Universidade Federal do Rio Grande do Norte

Laboratório de Desempenho PneumoCardioVascular e

Músculos Respiratórios

Departamento de Fisioterapia

CP 1524, Campus Universitário Lagoa Nova

CEP 59072-970, Natal, RN, Brasil

e-mail: vanessaresqueti@hotmail.com 